\title{
The Impacts of Transformational Leadership on Motivation of Employees: The Case of Employees at Vietnamese Small and Medium Enterprises
}

\author{
HUYNH THI THU SUONG \\ Faculty of Business and Administration \\ University of Finance and Marketing \\ 2/4 Tran Xuan Soan Str., Tan Thuan Tay Ward, Dis. 7, Hochiminh City \\ VIETNAM \\ Email: h.thusuong@gmail.com
}

\begin{abstract}
The purpose of this research is to explore and clarify the factors affecting transformational leadership style to employee motivation at Vietnamese SMEs. Meanwhile, propose solutions to develop transforming leadership style to increase employee motivation. In order to achieve the purpose of this study, a literature survey related to transforming leadership, job's satisfaction and employee motivation, their relations ware carried out. The research is based on a sample of 372 employees currently working at SMEs in Vietnam, 263 respondents are valid for research conducting. Using Cronbach's alpha analysis, Explore Factor Analysis (EFA) and Regression Analysis (RA) with primary data collected 263 valid from 372 employees in Vietnam. This paper explores and confirms that there are existed five factors have a positive effect on employee motivation. In particular, the most powerful factor is intellect stimulating, the weakest factor is the charismatic personality. From the above results, the author proposes the implications for increasing employee motivation at SMEs by transforming leadership style through five factors including charismatic personality, charismatic behavior, stimulation intellect, inspiring and personal attention. Results of the research show strong evidences for policy makers and enterprises for management in SMEs as well as its contribution to causes and effects between transforming leadership style and motivation of employees at Vietnamese SMEs. Key-Words: - Transformational Leadership, Motivation, SMEs, Vietnam
\end{abstract}

Received: October 27, 2019. Revised: February 19, 2020. Accepted: February 25, 2020. Published: February 28, 2020.

\section{Introduction}

In the current integration and development economy, human resources are considered as the most important factor, which is the decisive factor for success or failure, prestige, status, and ability of sustainable development of an organization or business. Therefore, all countries put human issues first. Today, organizations need not only highly quality human resources, but they also have to work hard and devote themselves to their business. Therefore, leader need to motivate employees contributing to their organization. If done well, employees' motivation will help businesses succeed and create their competitive position with competitors. According to Vietnam General statistics (3/2019), Vietnam has more than
600,000 small and medium-sized enterprises operating including 216,200 enterprises, accounting for $41.7 \%$ of the total number of enterprises in the country, most concentrated in the Southeast region. In particular, the most concentrated in the city. Ho Chi Minh City with 172,600 enterprises, accounting for $33.3 \%$ of the total number of enterprises in the country. The Red River Delta region ranks the second with 161,100 enterprises, accounting for $31.1 \%$ of the total enterprises of the country. The Central Highlands has the lowest number of enterprises, about 13,300 enterprises, accounting for about $2.6 \%$. Despite the rapid increase in number, the number of employees employed by SMEs has increased. On average, during the 2012-2018 period, the number of SMEs increased by $8.9 \%$, higher than the average 
growth of large enterprises of 5.3\%. In terms of labor size, the trend of smaller businesses also shows the characteristics of Vietnam, such as consistent with the turn of science and technology applications, especially the Industrial Revolution 4.0. Empirical evidence shows that the leadership style of the Vietnamese SMEs leadership team often includes senior, mid-level and a number of managers who are now transforming leadership styles. There have been many studies on motivational factors of employees, in which, the leadership style in general and the transforming leadership style in particular has a special impact on employee motivation. Specifically, studies of Almansour (2012) have demonstrated that 5 factors of leadership style transform directly affect employee motivation. Empirical research at SMEs Vietnam, the author found that most of the leaders at the Company have a transforming leadership style. This is reflected in things such as taking care of each individual employee, encouraging and providing financial and spiritual support when individuals or their families meet with difficulties, creating the best facilities for employees to work, sympathize and share. Especially always inspire positive staff, stimulate the brainpower, creativity of employees so that they are always eager to work. However, the leadership team at SMEs has not been deeply concerned nor aware of how to solve the problem of maximizing the transforming leadership style to create maximum motivation for employees. Based on the study of Ahmad, Abbas, Latif, \& Rasheed (2014) to measure the factors of transforming leadership style that affect employee motivation, through the transformation leadership style and from there propose the implications to promote the components of the transformation leadership style, motivate employee, stimulate employees to devote themselves and co-operate. It is also a premise for generations of leaders to maintain, implement and innovate in their work.

\section{Problem Formulation}

\subsection{Overview of Tranformational Leadership vs Motivation}

\section{Leadership}

Bass \& Riggio (2006) define leadership as a continuous process affecting employees. Leadership is a personal quality that inspires employees to achieve their goals. Management not only directs employees but also provides them with necessary assistance when they need it. Leadership is the process of influencing employees through directing and supporting employees to achieve the desired goals, on the other hand, the leadership's innate character also brings success in achieving the goals. Leadership is the process of promoting groups of individuals to progress in the same direction in noncoercive ways (Fry, 2003), leadership means using top-notch strategies to inspire and motivate employees to increase employee potential for growth and development. Leadership is the process by which an individually influences a group of people to achieve a common goal (Northouse, 2007). Leadership is the ability to influence a target group and direct them to a vision or set of goals. The role of leaders is regarded as the critical tools for the team members. The reason is that leaders play a vital role in formulating collective norms, assisting the team members to face and resolve the challenges arisen in the team environment. The critical importance of leaders on team member resulted in the creation new ways based on which leaders can provide value for the members of the team. In many cases, leaders are not aware of the main needs and wants of their subordinates, or they fail to understand the difference between the individuals involved in the team. As a result, due to the various issues that were not identified in time among team members result in the decreasing productivity of team members. 


\section{Transformational Leadership}

Transformational leadership involves using your own abilities to foster leadership potential in others. There are four types of leadership, known as the four I's, required to become a transformational leader. (i) Idealized Influence: Idealized influence, the first I, refers to a transformational leader's ability to lead by example. A good role model, she encourages her charges to adopt excellent leadership practices by acting as she wants them to act and doesn't ask them to do things she wouldn't do. Because they live up to their own expectations, transformational leaders earn admiration and respect from those they lead. (ii) Individualized Consideration: A transformational leader uses individualized consideration, the second I, when helping followers achieve their potential through coaching and mentoring. By performing this type of one-on-one leadership, he improves the organization's overall performance by helping staffers attain their individual goals. Transformational leaders genuinely care for their subordinates and want them to be successful. They earn the respect of their charges through effective one-on-one communication.

(iii) Inspirational Motivation: A transformational leader who can rally followers behind a cause demonstrates inspirational motivation, I number three. Because he can get workers excited about the organization's goals and vision, he successfully encourages them to work as a team to achieve those goals. (iv) Intellectual Stimulation: Intellectual stimulation, the last I, describes a transformational leader's ability to encourage out-of-the-box thinking. She motivates subordinates to take risks by displaying genuine interest in their efforts to develop creative breakthroughs. By creating an environment receptive to change, growth and new ways of thinking about business, transformational leaders foster entrepreneurship.
When employees are clear about their expectations and requirements, they are more likely to perform better. Although leaders are responsible for the proper task and job allocation, different leadership styles have several approaches how tasks are being allocated. Leaders are claimed to have a positive impact on the efficiency of the organization by influencing the team members. Particularly, leaders considerably influence its followers in the organization. Therefore, it is important to understand the nature of leadership styles such as transactional and transformational to assess their impact on resolving different organizational problems. May authors agree that most leadership models and practices are based on transfer processes, including a focus on communication between leaders and subordinates (Mohammed \& Wang, 2018).

Transformational leaders are reported to work based on the balanced approach This can be explained by the fact that they help their subordinates to solve some of the challenging issues at the same time they teach their subordinates about the ways of tackling the problems in the similar context. Therefore, researchers believe that role of the transformational leaders can be observed regarding bringing the motivational level of their employees to the stage of self-actualization. Moreover, most common qualities that are used to describe the personality of transformational leaders include charisma, intellectual stimulation (Suryanto \& et al., 2019). Another name for transformational leadership is a facilitator, in other words, in this case, team members and leaders motivate each other in order to achieve high levels of performance and motivations. Thus, it is considered as one of the most commonly adopted types of leadership where team members encourage each other by different means in order to achieve organizational goals and long-term plans. Unlike other types of leadership, this type of leadership has a high level of communication between the team members. Therefore, the case of transformational leadership was related to the increased levels of motivation, higher job satisfaction, commitment, productivity, and performance. Thus, transformational leader's control, vision, and enthusiasm inspiring its followers lead to higher results in the management. Regarding this context, the four essential components of the transformational leaders need to be reviewed. In the other hand, transforming leaders mingle with their employees to create connections that increase motivation and morality not only for subordinates, but for the leader himself. According to Bass (1997), leadership is the most important factor in the success or failure of an organization. Thus, the role of a leader with his leadership style has a great influence 
on the success, development orientation, operational strategy, culture and future of the organization. Leadership transformation is like an influential process to raise employees' awareness of important issues. Facing environmental opportunities and challenges, leadership transforms in a new way, proactively seeking ways to optimize individuals, groups, organizational development and innovation to achieve results. only reach the performance level "at the expected point". The transforming leader does not replace the transfer for leader, however increases the achievement of the group's goals. (Yukl, 1989) defines transformation leadership as a process that greatly influences the change in organizational members' attitudes and assumptions and builds a commitment to an organization's mission and goals. The role of leaders is emphasized in influencing their employees (Yukl, 1999). Leadership in a transformative style has the ability to encourage employees to achieve higher, more valuable goals for the organization, including greater productivity, better service, and resolution. problems of society. This is the type of leadership where employees will be motivated, inspired to work, develop their ability to voluntarily strive to achieve the organization's common goals. This type of leadership will increase employee performance, make them happy with their job and want to stay with the company for a long time. When employees see leaders who themselves are also trying to achieve the goals of the organization and they themselves receive support from leaders will help them be more motivated to work. People in this leadership style must know what their employees need and give them the opportunity to become a leader. By knowing what their employees need, leaders can meet the needs of their employees, thus making them want to work more. At the same time, creating opportunities for employees to lead will make employees feel that they are a part of the organization so that they feel that the work they are doing is not to achieve the leadership goals or of organizations that are to achieve their own goals. Then they will be more responsible for their work and willing to sacrifice personal benefits for the organization. Instead of blaming an employee for a mistake, the leader can work with the staff to fix the error and help them learn experience in order help them don't make the same mistake again. According to Bass, Avolio, Jung, \& Berson, (2003), new leaders of quality will focus on developing followers by exploiting their potentials, inspiring them, promoting cooperation, motivating them and reinforce positive behaviors and attitudes. The staff has a high level of trust and confidence in the leader. The employees are very proud to assert themselves with the leaders and

develop a strong sense of loyalty to them. Quality leadership is based on five factors. Charismatic personality; charismatic behavior; intellectual stimulation; inspire and personal attention. Attractive personality (Idealized influence - Attributed): Demonstrated through prestige, confidence, strong, ethical, powerful, the importance of leadership in the organization. When a reputable leader will influence the employees' beliefs to help them have a mental, moral, and power base, they will respect the leader and obey the command from which to work peacefully. like giving your all to the job. Idealized influence (Behavior): The charismatic action of leaders demonstrates the values, beliefs and sense of responsibility to increase respect and trust. With this factor, the leader becomes an example in compliance with the regulations as well as enthusiasm in the work, showing professional style and belief in the success of the goals set by the organization. From there, employees will feel and learn the way of leadership voluntarily help them improve their skills at work in a natural way. Intellectual Stimulation: Leadership motivates employees to be more creative and work more effectively. Leaders always guide employees to find solutions of problems better than traditional ways. This stimulates employees to work creatively and logically. With this factor, leaders always encourage and create conditions for employees to express initiatives while respecting their opinions. Since then, employees have always seen their own values following their initiatives. This brings an improvement in the effectiveness of the organization's work and operations.

Last but not least, we can look at t-statitics values below (Abasilim et al. 2019). Results show the highest of leadership style scores among respondents within the age group 20 to 30 years, single, OND, junior staff, and among respondents who had less than 5 years of experience compared with the other categories.:

Category $\mathrm{n} \quad \mathrm{X} \quad \mathrm{SD} \quad \mathrm{SE}$ of mean t-calc

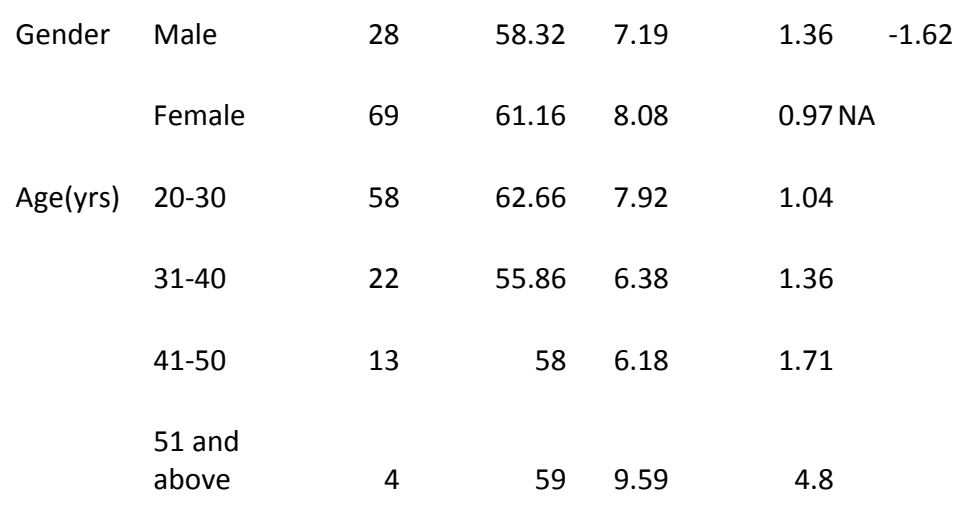




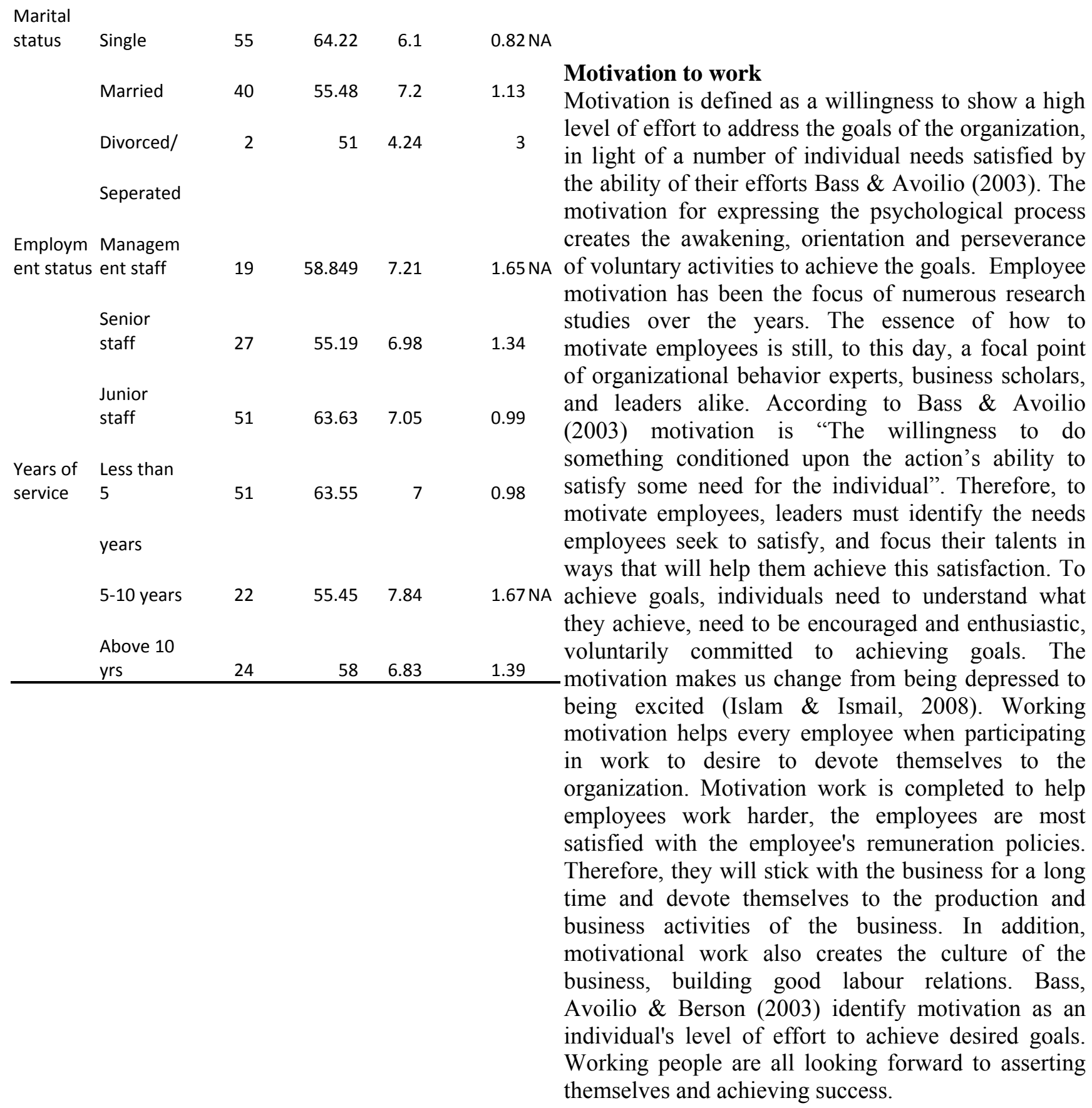


When people are in different positions, with different psychological characteristics there will be different desires. Leaders need to learn the different ways to influence each employee. The effective promotion of motivation in people will lead to positive actions, high efficiency and vice versa. Motivation is the desire and willingness of the person to increase the effort to achieve a goal or can understand in other words, motivation is the impulse from within each person, motivating people to act. According to Robbins, the three main components of motivation are intensity, orientation and endurance. Intensity describes the level of effort a person makes, which most of us focus on when it comes to motivation. In another way, there are two basic types of motivation: intrinsic motivation and extrinsic motivation. Newstrom and Davis (2002) discussed the difference between intrinsic and extrinsic motivators. "Intrinsic motivators are internal rewards that a person feels when performing a job, so there is a direct and often immediate connection between work and rewards". This type of motivation usually leads to an employee becoming self-motivated or energized from within to perform their best and make a valuable contribution to the organization or society. Extrinsic motivators are different than intrinsic motivators. "Extrinsic motivators are external rewards that occur apart from the nature of work, providing no direct satisfaction at the time the work is performed" (Newstrom \& Davis, 2002). Examples of extrinsic motivators include salary increases, fringe benefits, and leave time. Although employees value these types of extrinsic rewards, Newstrom and Davis suggested that they are not effective motivators. However, according to research by Crewson (1997), extrinsic motivators do have an impact on employee motivation, particularly in the private sector.

\section{The relationship between transforming leadership style and work motivation}

A number of systematic studies used to connect transformational leadership practices and work motivation are conducted in different countries in different areas of the world. Gopal \& Chowdhury (2014) have demonstrated that a transforming leadership style has a positive impact on employee motivation at the Indian oil company. Ahmad et al. (2014) in Punjab with telecom employees, this study also concluded that transforming leadership style has a strong influence on employee motivation. In the banking sector show that leadership style transforms a significant, positive and strong impact on employee motivation. Overall, the topic of leadership style and employee motivation has attracted the attention of many researchers around the world. Based on the theoretical foundations above and the results of the above studies have proved that there is a relationship between transformational leadership style and work motivation. Specifically, transforming leadership style will help employees be motivated, inspired to work, develop their abilities, stimulate creativity and be interested. As a result, leadership contributes to motivate employees to work harder, be more productive, more efficient and create values for the Company.

\subsection{Framework of Transformational Leadership}

\section{Structure of transformational Leadership}

It is accepted that SMEs play an important role in economic growth in emerging economy as Vietnam. For example, Vietnamese SMEs represent $91.8 \%$ of the number of businesses of the country; employ 77 percent of the workforce and account for $80 \%$ of the retail market, has significantly contributed to the economy and account for $95 \%$ of all business establishment, nearly $75 \%$ of total employment, and nearly $43 \%$ of total GDP. Yet the question of whether employees in SMEs getting more or less motivation in their job is still unclear. In Vietnam, SMEs have possessed a number of strengths that could contribute to their capacity to increase productivity. The study compares the perceptions toward leadership, workplace motivation in Vietnamese SMEs. A survey was completed by 263 respondents drawn from Vietnamese SMEs. The survey was comprised of the Design Leadership Questionnaire (DLQ), the Workplace motivation. The Cronbach's alpha values for each instrument were $\alpha$ from 0.7 (Design Leadership), $\alpha-0.8$ (Workplace Motivation). T-test results found that there was a statistically significant difference in the mean scores of transformational leadership styles and all of its dimensions. Also, the significant differences are found in the mean scores of Workplace Motivation and all of its dimensions' Vietnamese respondents. The findings provide empirical evidence to advance our understanding of the impact of work values on transformational leadership styles and workplace motivation and assists in developing government policy to further SMEs leadership methods for Vietnamese managers to lead their subordinates towards motivation practices. 


\section{Types of transformational Leadership}

There are a number of different styles of leadership and management that are based on different theories. Inspirational The individual style will be used basing on a combination of their beliefs, values and preferences, as well as the organizational culture and norms which will encourage some styles and discourage others. Northouse (2001) defined that the transformational leadership is a process that changes and transforms individuals. Additionally, the transformational leadership is the ability to get people to improve, to change and to be led. It involves assessing associated motives, satisfying their needs and valuing them (Frances and Cohen, 1999). Hence, a transformational leader could improve the company performance and make more successful of the company objectives. Sidani (2007) mention that there are four factors to transformational leadership which are idealized influence, intellectual stimulation, inspirational motivation, and individual consideration. Each of these factors can help managers to use this approach in the workplace including (i) Idealized influence: describes managers who are exemplary role models for associates. Managers with idealized influence can be trusted and respected by associates to make good decisions for the organization; (ii) Intellectual Stimulation: describes managers who encourage innovation and creativity through challenging the normal beliefs or views of a group. Managers with intellectual stimulation promote critical thinking and problem solving to make improvement of organization performance; (iii) Inspirational motivation: describes managers who motivate associates to commit to the vision of the organization. Managers with inspirational motivation encourage market growth for the organization; (iv) Individual consideration: describes managers who act as coaches and advisors to the associates. Managers with individual consideration encourage associates to reach goals that help both the associates and the organization".

\subsection{Proposed Research Model}

From empirical observation of SMEs in Vietnam, the author has found that the current leadership is adopting a transforming leadership style into practice, which helps the company's sales grow strongly and develop in future. The author found that the leadership style currently applied fully carries the elements of the transformation style including: (i) Attractive personality: Leaders of the company will show employees the leader himself not only has the ability but also the mind and the virtue for the employees to follow; (ii) Enticing behavior: The leaders of the company will be a good example for all employees to follow in order to do well the assigned work; (iii) Inspired characteristics: The leaders must show employees the vision, development orientation of the company, inspire his enthusiasm by rewarding activities when fulfilling the work goals; (iv) Intellectual stimulation: This is done specifically by leaders such as creating a dynamic, creative working environment, organizing training courses, fostering employees' capacities, providing bonus when employees have new contribution ideas; (v) Personal attention: This is reflected in the insurance for family members of some disadvantaged employees, the policy of encouragement to visit when employees are sick or accident. , birthday gifts for staff. In addition, they often exchange experiences and talk with employees to capture their thoughts and aspirations, creating opportunities for them to work better. From previous studies such as Gopal \& Chowdhury (2014); Ahmad et al. (2014), Rawat, (2015) combines practical assessments of leadership styles affecting employee motivation at SMEs Vietnam, showing that elements of transformative leadership styles are influential employee motivation. The author proposed a research model similar to Ahmad et al. (2014) from which to measure testing in the case of application at SMEs Vietnam. Although there are many similar and different studies with Ahmad's research, the author decided to choose Ahmad's research model to conduct research because the model has all five elements of transformational leadership style and the main purpose is to motivate employees. From the study of published research concerning, motivation showed that lots of factors affecting in different aspects. In this study combining literature review and experimental basis, five factors enable to create a model research for Vietnamese SMEs as follows 


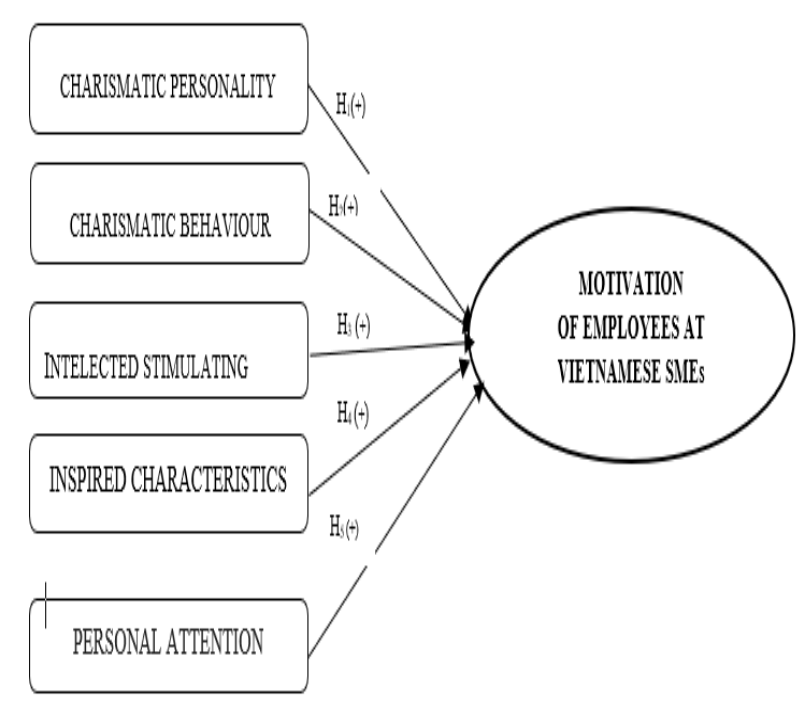

Source: Qualititive research results by Suong (2019)

From the initial proposal model, the author uses survey data to process and inputs exploratory factor of analysis to identify factors that affecting of transformational leadership to motivation before having initial research model.

\subsection{Research Methodology}

This research was conducted basing on two methods: (i) Qualitative research aims to construct, calibrate the component scale: Charismatic personality, Charismatic behavior, Intelected stimulating, Inspired and Personal attention of transformational leadership impacting on motivation. (ii) Quantitative research aims to collect, analysis survey data, as well as testing the component scale, measuring the research theory model and hypothesis. Preliminary research is built and calibrated by scale and added the observation variables through qualitative and quantitative methods. Preliminary qualitative research is done by expert with great consideration and group discussions with managers having concern with dairy industry by the sampling method. The content of the discussion related to the factors that effected integration of actors in the workforce motivation which relates to factors influence on integration of transformational leadership; comment on; give out the research model for the discussion group to comment on the factors that affect the workforce motivation and the draft scale built up by the author group and corrected by the discussion group.
After exchanging ideas, the discussion group agreed with the proposed model and also recommended to calibrate some of the names in the scale components, and proposed to amend the scale, modify some observed variables. From that, the research discussion group has agreed about five factors that affect motivation of employees at Vietnamese SMEs. The scale of the research model included 39 observation variables measured by Likert scale 5 in which points with 1 - completely disagree to 5 - completely agree.

\section{Problem Solution}

\subsection{Problem}

Data is collected through online survey forms in 12 weeks. 263 questionnaires are valid. Collected data is processed and have descriptive statistics as follows: 
Table 1. Descriptive statistics Results

\begin{tabular}{|c|c|c|c|}
\hline \multicolumn{2}{|r|}{ Demographic feature } & \multirow{2}{*}{$\begin{array}{c}\begin{array}{c}\text { Frequen } \\
\text { cy }\end{array} \\
144\end{array}$} & \multirow{2}{*}{$\begin{array}{c}\% \\
54.7\end{array}$} \\
\hline Gender & Female & & \\
\hline & Male & 119 & 45.3 \\
\hline \multirow[t]{5}{*}{ Age } & $\begin{array}{l}\text { From } 18 \text { to below } 22 \\
\text { years old }\end{array}$ & 5 & 1.9 \\
\hline & $\begin{array}{l}\text { From } 22 \text { to below } 30 \\
\text { years old }\end{array}$ & 106 & 40.3 \\
\hline & $\begin{array}{l}\text { From } 30 \text { to below } 40 \\
\text { years old }\end{array}$ & 110 & 41.8 \\
\hline & $\begin{array}{l}\text { From } 40 \text { to below } 50 \\
\text { years old }\end{array}$ & 30 & 11.4 \\
\hline & Above 50 years old & 12 & 4.6 \\
\hline \multirow{4}{*}{$\begin{array}{c}\text { Level of } \\
\text { education }\end{array}$} & High school & 2 & 0.8 \\
\hline & $\begin{array}{l}\text { Job training school/ } \\
\text { college }\end{array}$ & 58 & 22.0 \\
\hline & University & 189 & 71.8 \\
\hline & $\begin{array}{l}\text { Postgraduate } \\
\text { education }\end{array}$ & 14 & 5.4 \\
\hline \multirow{4}{*}{ Salary } & Below 7 million VND & 19 & 7.2 \\
\hline & $\begin{array}{l}\text { From } 7 \text { to below } 12 \\
\text { million VND }\end{array}$ & 186 & 70.7 \\
\hline & $\begin{array}{l}\text { From } 12 \text { to } 16 \text { million } \\
\text { VND }\end{array}$ & 43 & 16.3 \\
\hline & $\begin{array}{l}\text { Above } 15 \text { million } \\
\text { VND }\end{array}$ & 15 & 5.8 \\
\hline \multirow{5}{*}{$\begin{array}{c}\text { Seniority } \\
\text { at } \\
\text { enterprises }\end{array}$} & Below 3 years & 26 & 9.8 \\
\hline & From 3 to 5 years & 49 & 18.6 \\
\hline & From 5 to 7 years & 173 & 65.9 \\
\hline & From 8 to 10 years & 12 & 4.6 \\
\hline & Above 10 years & 3 & 1.1 \\
\hline
\end{tabular}

Source: Results from the data process of Suong (2019)

\section{Reliability Analysis}

Table 2. Table summarizes the results tested by Cronbach's alpha scale

\begin{tabular}{|c|c|c|c|}
\hline \multirow{2}{*}{ Scales } & \multicolumn{2}{|c|}{ No. of items } & Cronbach's \\
& alpha \\
\hline CHP & 5 & 4 & 0.841 \\
\hline CHB & 5 & 4 & 0.867 \\
\hline INS & 4 & 4 & 0.884 \\
\hline INC & 4 & 3 & 0.705 \\
\hline PEA & 4 & 3 & 0.722 \\
\hline MOT & 3 & 3 & 0.801 \\
\hline
\end{tabular}

Source: Results from the data process by Suong (2019)

\section{Explore Factor Analysis and Regression Analysis}

The Cronbach's alpha was conducted to assess the reliability of each scale. Alpha values average 0.8 for one dependent variable and the other eight independent variables. This indicates all scales can be considered reliable (Creswell, 2002). For each of the item scales, factor analysis was used to reduce the total number of items to manageable factor. Principal components analysis is used to extract factors with eigenvalue is 1.109. Varimax rotation is used to facilitate interpretation of the factor matrix. Sampling adequacy measurement tests are also examined via the KMO statistics to validate the use of factor analysis. The composition of independent variable scales, with sig. $=0.000$ and $\mathrm{KMO}=0.748$, the variables converge to 8 differentiating factors such as the original hypothesis and the total deviation of $66.35 \%$ for the deduction of $64.27 \%$. Measurement variables with weighting factors of variables are greater than 0.5. From the above results, the weighting factors of variables and the total deviation satisfy the theoretical condition so it can be concluded that the appropriate EFA model, the variables will continue to be included in the regression analysis.

Table 3. Results of Exploratory Factor Analysis with eight-factor model

\begin{tabular}{|c|c|c|c|c|c|}
\hline $\begin{array}{c}\text { Conce } \\
\text { pt }\end{array}$ & $\begin{array}{c}\text { Variable } \\
\text { s }\end{array}$ & $\begin{array}{l}\text { Obse } \\
\text { rvers }\end{array}$ & $\begin{array}{c}\begin{array}{c}\text { Cronbath } \\
\text { 's }\end{array} \\
\text { alpha }\end{array}$ & $\begin{array}{c}\text { Cumula } \\
\text { tive } \\
\text { Varianc } \\
\text { e (\%) }\end{array}$ & $\begin{array}{c}\text { Conclusi } \\
\text { on }\end{array}$ \\
\hline \multirow{5}{*}{$\begin{array}{l}\text { Motiva } \\
\text { tion } \\
\text { (MOT) }\end{array}$} & CHP & 4 & 0.841 & \multirow{5}{*}{64.27} & \multirow{6}{*}{ Accepted } \\
\hline & $\mathrm{CHB}$ & 4 & 0.867 & & \\
\hline & INS & 4 & 0.884 & & \\
\hline & INC & 3 & 0.705 & & \\
\hline & PEA & 3 & 0.722 & & \\
\hline \multicolumn{2}{|c|}{$\begin{array}{l}\text { Employees } \\
\text { motivation }\end{array}$} & 3 & 0.801 & 68.216 & \\
\hline
\end{tabular}


Using Pearson's correlation coefficient to analyze the correlation between independent variables, results show the correlation between independent variables and dependent variables were positive. Next, conducting a regression analysis, results of the model confirmity assessment are as follows:

Table 4. Model Summary

\begin{tabular}{|l|c|c|c|c|c|}
\hline Model & $\mathrm{R}$ & $\begin{array}{c}\mathrm{R} \\
\text { Square }\end{array}$ & $\begin{array}{c}\text { Adjusted } \\
\text { R Square }\end{array}$ & $\begin{array}{c}\text { Std. Error } \\
\text { of the } \\
\text { Estimate }\end{array}$ & $\begin{array}{c}\text { Durbin- } \\
\text { Watson }\end{array}$ \\
\hline 1 & $.802^{\mathrm{a}}$ & .718 & .653 & .234 & 1.978 \\
\hline
\end{tabular}

a. Independent Variable: CHP, CHB, INS, INC, PEA

b. Dependent Variable: MOT

VIF values of the observed variables are both $<2$, so it can be concluded that the model may not be affected by the multicollinearity phenomenon. The model remains five (05) factors fit the model with the significance level from 0.000 to 0.006 are less than 0.05 . The standardized regression coefficients (Beta) of the remaining factors are positive $(+)$, indicating the same directional impact as integration, which means that when the value of the factors is high, integration is also highly correlated. Beta also said the level of impact on sequential motivation from high to low is: Charimatics Personal (CHP), Charimatics Behaviour (CHB), Intelected Stimulating (INS), Inspired Characteristics (INC), Personal Attention (PEA). From the results of the aboved test, we obtain the non-standardized regression equation of the following form: Therefore, we can conclude that 5 above variables have a strong relationship with the dependent variable. Basing on unstandardized Beta column, variables can be explained by the following linear equation:

\section{MOT $=-0.432+0.294$ INC $+0.266 \mathrm{CHB}+$ 0.232CHP + 0.213INS + 0.158PEA}

\subsection{Solution}

This integrative literature review provides an overview and critique of the field of work motivation. This review is limited by the key phrases used for searching, the databases accessed, the frame and method of searching for literature, and time constraints. This review is also based on a broader scope of work motivation representing many job sectors instead of focusing in a particular job sector.
According to research results, motivation does not differ for employees regardless of age, level, gender, department as well as seniority. Therefore, the authors think that the leadership should have policies as well as changes to create motivation for employees to be most effective including: (i) There should be preferential policies for employees training courses or support tuition if the employee needs to raise the level. Increase employee income proportional to job completion. This will help the working motivation of office staff higher than other departments, creating tremendous value for the company. (ii) Leaders at SMEs should have the property incentive for employees both physical and mental properly, especially create a comfortable and dynamic working environment. Leaders must set an example and know how to inspire staff enthusiasm to work effectively.

SMEs' leaders need to know employees' needs and their desirers through the roles of leaders and looking for the right methods to match their desires. If doing well this issue will contribute to increasing the motivation of employees' work, helping employees work better, more efficiently, and SMEs are increasingly stable developing. It can be concluded that employ motivation is a key to success for every organization and employ motivation can be achieved through transformational and charismatic leadership. Idealize Influence, Employee motivation is strongly effected with dimension of Transformational Leadership. Only those employee which have developed level of self efficiency, self-respect and motivation when given Idealize Influence, Individual Consideration, Intellectual Stimulation and Inspirational Motivation. Individual Consideration, Intellectual Stimulation and Inspirational Motivation. When all dimension of Transformational Leadership adapted by management it leads to higher employee motivation in any sector at SMEs in Vietnam. It is examined that motivation can a chance to be proficient through sure conduct technique. At last it may be accepted that it is all in the hand of organization to keep the employees motivated to work because they can develop such policies that lead to motivation of employees.

\section{Conclusion}

Worker motivation is a complex process and crosses many disciplinary boundaries, including economics, psychology, organizational development, human 
resource management, and sociology. By drawing attention to this broad range of influences, this paper aims to help policy makers view worker motivation in a more holistic manner. This broader view will enable them to structure reform programs to more effectively promote employees motivation, and hence, improve their performance. Each country must analyze its own particular constellation of organizational structures, culture, and broader societal culture to determine how best to approach the design and implementation of their particular job reform. Often, reform programs have focused on a very limited number of channels (e.g. financial incentives) to influence worker behaviour, and neglected other less tangible incentives, such as the work itself, achievement, and recognition. Many of these reforms have resulted in little improvement in worker motivation, or even in reductions in motivation due to unanticipated influences. Last but not least, future artificial intelligence (AI) leadership can require adjustments to motivate employee to be more active and effective at work and behaviours such as charismatic influences and relationship building are important for leading humans.

\section{References:}

[1] Ahmad, F., Abbas, T., Latif, S., \& Rasheed, A. (2014). Impact of Transformational Leadership on Employee Motivation in Telecommunication Sector. Journal of Management Policies and Practices, 2(2), 11-25. https://doi.org/10.1038/166711a0

[2] Almansour, Y. M. (2012). The relationship between leadership styles and motivation of managers conceptual framework. Journal of Arts, Science \& Commerce, 3(1), 161-166.

[3] Al-Malki, M. \& Juan, W. (2018), Leadership Styles and Job Performance: a Literature Review, Journal of International Business Research and Marketing, Volume 3, Issue 3, journal homepage: www.researchleap.com

[4] Aziri, B. (2011), Job satisfaction: A Literature Review, Management Research and Practice, Volume 3, Issue 4, PP: 77-86 (2011)

[5] Bass, B. M. (1997). Does the transactionaltransformational leadership paradigm transcend organizational and national boundaries? American Psychologist, 52(2), 130-139.

[6] Bass, B. M., Avolio, B. J., Jung, D. I., \& Berson, Y. (2003). Predicting unit performance by assessing transformational and transactional leadership. Journal of Applied Psychology,
88(2), 207-218. https://doi.org/10.1037/00219010.88.2.207

[7] Bass and Riggio's (2006), Transformational Leadership Model as a means of Leader-renewal at the Napa Community Seventh-day adventist church, Ph.D Thesis, Andrews university.

[8] Bass, B. M., \& Avoilio, B. J. (1994). Improving organizational effectiveness through transformational leadership. Thousand Oaks, CA: Sage Publications.

[9] Bass, B. M., \& Avoilio, B. J. (2003). The multifactor leadership questionnaire report. Palo Alto, CA: Mind Garden.

[10] Bass, B. M., Avoilio, B. J., Jung, D. I., \& Berson, Y. (2003). Predicting unit performance by assessing transformational and transactional leadership. Journal of Applied Psychology, 88(2), 207-218.

[11] Bass, B. M. (1985). Leadership and performance beyond expectations. New York, NY: The Free Press. Bass, B. M. (1999). Two decades of esearch and development intransformational leadership. European Journal of Work and Organizational Psychology, 8(1), 9-32.

[12] Crewson, P. E. (1997). Public-service motivation: Building empirical evidence of incidence and effect. Journal of Public Administration Research and Theory, 7(4), 499518.

https://doi.org/10.1093/oxfordjournals.jpart.a024 363

[13] Fry, L. W. (2003). Toward a theory of spiritual leadership. Leadership Quarterly, 14, 693-727. https://doi.org/10.1016/j.leaqua.2003.09.001।

[14] Hamoud, A.K., Hussien, H.N., \& Jasim, E.T. (2019). International Journal of Economics and Staitisctis, 7, 70-82.

[15] Islam, R., \& Ismail, A. Z. H. (2008). Employee motivation: A Malaysian perspective. International Journal of Commerce and Management, 18(4), 344-362. https://doi.org/10.1108/10569210810921960

[16] Gopal, R., \& Chowdhury, R. G. (2014). Leadership styles and employee motivation: An empirical investigation in a leading oil company in India. International journal of research in business management, 2(5), 1-10.

[17] Newstrom, J. W., \& Davis, K. (2002). Organizational behavior (1 Ith ed.). New York: McGrawHill Higher Education. 
[18] Northouse, P., G. (2001). Leadership Theory and Practice, (2nd edition). Thousand Oaks, CA:

Sage Publications, Inc

[19] Northouse, P. G. (2007). Transformational leadership. Leadership: Theory and practice, 4 , 175-206.

[20] Rawat, S. R. (2015). Impact of transformational leadership over employee morale and motivation. Indian Journal of Science and Technology, 8(S6), 25-34.

https://doi.org/10.17485/ijst/2015/v8iS6/62118

[21] Sidani, Y. M. (2007). Perceptions of leader transformational ability: The role of leader speech and follower self-esteem. Journal of Management Development, 26(8), 710-722. https://doi.org/10.1108/02621710710777237

[22] Yukl, G. (1989). Managerial Leadership: A Review of Theory and Research. Journal of Management, 15(2), 251-289. https://doi.org/10.1177/014920638901500207

[23] Yukl, G. (1999). An evaluation of conceptual weaknesses in transformational and charismatic leadership theories. Leadership Quarterly, 10(2), 285-305. https://doi.org/10.1016/S10489843(99)00013-2

[24] Vietnam General Statistics (2017), available at: https://www.gso.gov.vn/default_en.aspx?tabi $\underline{\mathrm{d}=487 \& \mathrm{idmid}=\& \text { ItemID }=8390 \text { ) }}$ 